\title{
Accidents are caused, they do not happen
}

\author{
Dr Mahesh Chand Meena*, Dr. Nidhi Sachedeva, DrMukta Rani, DrYashoda Rani
}

Department of forensic medicine \& toxicology, LadyHardingeMedicalCollege \& Assoc.Hospitals, New Delhi-110001, India

*drmahe2012@gmail.com

\begin{abstract}
The head, being the most vulnerable part of human body, is the most commonly injured body part in accidents, especially those involving road traffic. In an unusual case, the deceased succumbed to internal injuries of the brain that resulted from the neck being constricted with the loose end of a dupatta. The woman was pillion riding a motorbike when the loose end of the dupatta got entangled in the rear wheel of the motorbike. As a result, her neck was constricted by the dupatta and wentunnoticed. This paper comments on the safety of wearing the traditional style dressing of Indian women while riding on two wheeled vehicles. Additionally, this paper suggests it be mandatory to wear helmets for all pillion riders in order to prevent such mishaps in future.
\end{abstract}

Keywords:

Pillion rider, Helmet, Dressing, two-wheeler, head injury

\section{INTRODUCTION}

In the past, there have been incidences where the loose ends of clothing have gotten tangled in a rotating wheel or other moving part of machinery and have caused serious injury (Aggarwal NK et al, 1998, Kohli A et al.1996, Siddiqui AA et al, 2006, Aggrawal A 2007). There are cases on record which explain events of clothing getting entangled in a cyclepowered rickshaw (Aggarwal NK et al, 1998, Kohli A et al, 1996, Siddiqui AA et al, 2006, Anil Aggrawal 2007, Gowens PA et al, 2003), a thresher machine (Jain V, 2007) and even an animal, (Verma SK et al 2005) which caused such a bizarre form of accidental strangulation.

Incidents of accidental strangulation of the neck are fatal in most instances. This type of injury may present a spectrum of lesions, with the result rarely limited to the superficial tissues of the neck region. This was the scenario in our case. Sometimes, severity of such injuries may extend to the fracturing of the hyoid (Gowens PA et al, 2003) or the cervical vertebrae of the spine. Moreover, the lesions may involve laryngeal rupture and carotid artery stenosis (Isadora Duncan syndrome) (Gowens PA et al, 2003). The type of case from our study is a rarity, where the victim accidently succumbed to head injury as a consequence of constriction of the neck by loose clothing. The victim was immediately rushed to a nearby hospital and declared dead on arrival.

It is imperative to reconstruct the scene of the incident, as the constrictive abrasions of the neck region may simulate homicidal strangulation and lead to unnecessary investigation by law governing officials.

Various researchers have emphasized the role of adopting certain safety measures as precautionary means ranging from the use of plastics in the rear wheel of two wheeled vehicles, to a word of caution to women while on such a vehicle in regards to wearing loose flowing dresses (Gowens PA et al, 2003, Gupta BD et al 2004).

Needless to say, spreading awareness among the public with specific programs and training manuals, which guide them on how to handle such cases, is the most important step. This training would include various aspects of safety, from how to immediately loosen the constricting agent, to appropriate first aid services at the site of incident.

\section{CASE REPORT}

A 30-year old woman, who was pillion riding on a two-wheeled vehicle, suddenly landed right in the middle of the road when the loose end of her dupatta (A long scarf worn by Indian women) got entangled in the rear wheel of the motorbike when (Figure 1). She was pronounced dead on arrival at the nearby Willingdon (Dr Ram ManoharLohia) Hospital, in New Delhi.

At autopsy, external examination revealed a semicircular ligature mark in the front of the neck and multiple graze abrasions, $5 \mathrm{~cm} \times 3 \mathrm{~cm}$, on the superior - medial surface of left shoulder (Figure 2). There was evidence of a sub-scalpal hematoma over the occipital area of head. Brain parenchyma

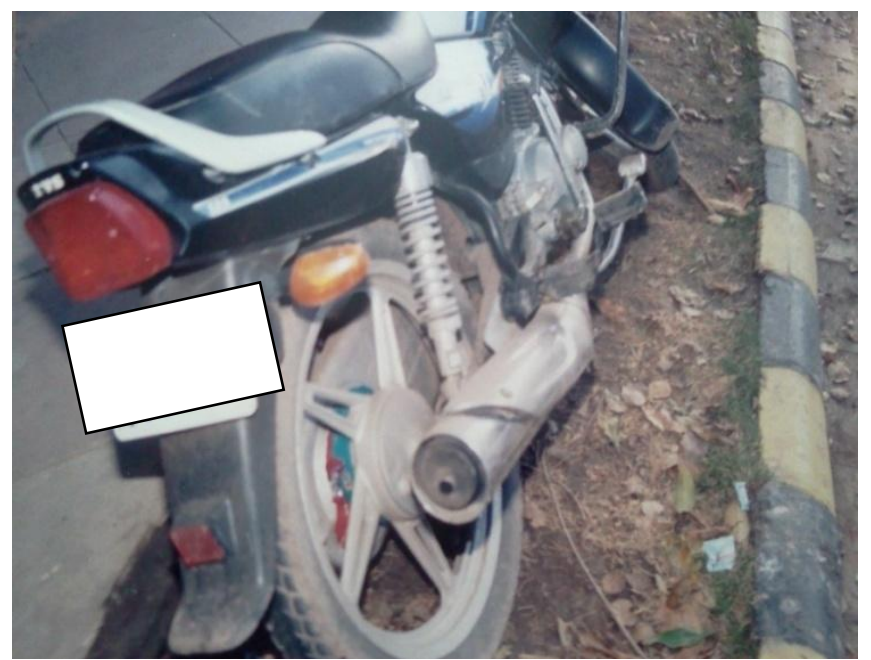

Figure 1. Right side view of the vehicle. See the entangled cloth (chunni) in the rear wheel. 
was suggestive of a thin film of subdural hemorrhage coexisting with subarachnoid hemorrhage over entire cerebrum (Figure 3). In the skull, a $7 \mathrm{~cm}$ linear fracture involving the left area of posterior cranial fosse was evidenced.

\section{DISCUSSION}

Each year in the United States, approximately 900 people die from injuries due to bicycle crashes and over 500,000 persons are treated for these types of injuries in emergency departments. Head injury is by far the greatest risk posed to bicyclists, comprising one-third of emergency department visits, two-thirds of hospital admissions, and three-fourths of deaths (ThompsonDC, Rivara1 F, Thompson R http://www.thecochranelibrary.com ). In another study, head injury occurred in 59 (42\%) of the 139 of riders without helmets compared to only 7 (9\%) of the 75 helmeted riders. Although it makes inherent sense that helmets would be protective against head injury, establishing the real-world effectiveness of helmets is important.

Today, helmet laws are universal for motorcyclists in 20 U.S. states and the District of Columbia and Ohio mandates helmet use only for riders or passengers under the age of 17 years ( Shutter LA, Kempisty SM, RN, Johannigman JA, Narayan RK. Unhelmeted Motorcyclists: Higher Mortality Morbidity, and Costs).

In this case, the woman who had succumbed to head injury was not wearing a helmet or any kind of headgear, which could have saved her life. Various studies are conducted in India and developed nations comparing the amount of injuries occurring in unhelmeted riders. The Centre of Biomedical Engineering, IIT, in New Delhi, India has shown that brain injuries are seen among $50-80 \%$ of motorcyclists and those without helmets were found to be at higher risk of sustaining brain injuries compared to helmeted riders (Mohan D, 1983, 1992). In an another study at NIMHANS (National Institute of Mental Health \&Neuro Sciences), mortality among riders and pillions without helmets was 2.2 times higher compared to helmeted riders (Gururaj G et. al,1993, Channabasavanna SM et.al,1994).In addition to the above studies, various researchers have reported cases pertaining to injuries involving the neck where the neck was constricted by a loose part of clothing worn by the victim. These researchers have suggested methods of preventing such mishaps in the future (Deidiker R.D, 1999)

Public education should be available regarding which types of clothing are suitable to wear while using these types of vehicles. Similarly, there should be some public announcements regarding how to use these vehicles in a safe manner or suggestions regarding possible changes in the design of vehicles and machines, which can help prevent such accidents and save further loss of life.Even though the occurrence of such cases is not very high, they continue to be important because they are preventable.

In the present case there are two safety aspects. Firstly, the dupatta could have been tied tightly, leaving no loose end to float in the air. Secondly, the mesh guard on the rear wheel could have been on both the sides of the wheel. There is a need to develop a comprehensive and integrated approach to make two wheeled vehicle riders safe. Helmet legislation is one of the most important strategies to reduce brain and facial injuries and deaths within this group.

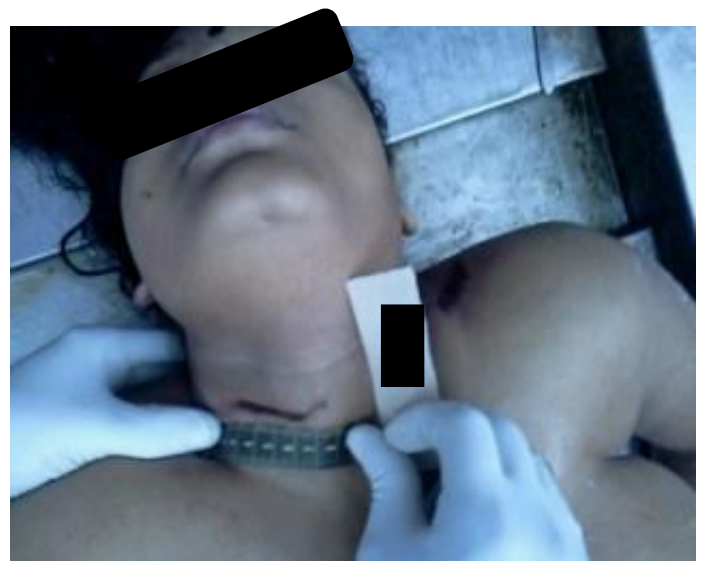

Figure 2. The view of the ligature mark and pressure abrasions on the right side of the neck.

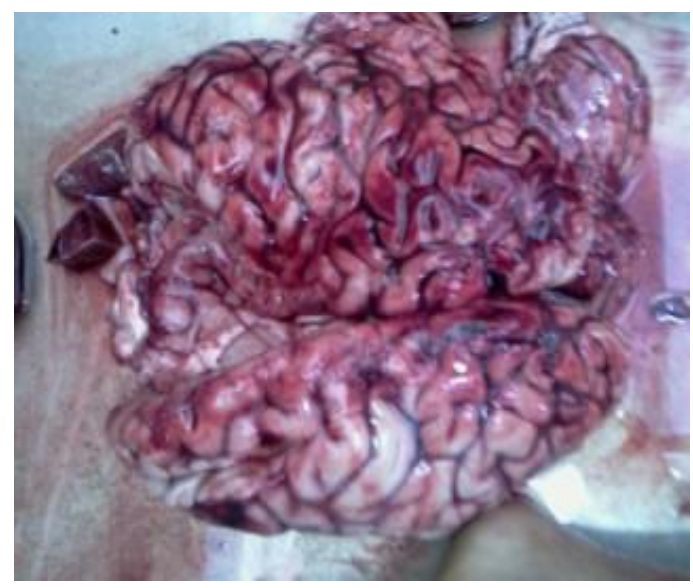

Figure 3. Brain shows a thin film of Subarachnoid haemorrhage over entire cerebrum

\section{CONCLUSION}

This case stresses the role of awareness in the form of public education regarding precautions to be taken in the particular manner of motor vehicle accidents involving pillion riders. Wearing helmets should be made mandatory for all pillion riders along with the concordance of other safety measures. In addition, improvement in the design of vehicles may add to the safety of the rider.

\section{ACKNOWLEDGEMENTS:}

Kristen Boyd is kindly thanked for language revision. 


\section{REFERENCES}

[1] Aggarwal NK, Agarwal BB.Accidental strangulation in a cycle rickshaw. Med Sci Law, 1998; 38:263-5.

[2] Channabasavanna SM and Gururaj G. Head Injuries and Helmets: Implications for Policies in Developing Countries. Journal of Police Research and Development, 1994;19-24,

[3] Deidiker R. D. Accidental ligature strangulation due to a roller type massager device. Am. J. Forensic Med. Pathol. 1999; 20 (4): 354-6.

[4] Gowens PA, Davenport RJ, Kerr J, Sanderson RJ, Marsden AK. Survival from accidental strangulation from a scarf resulting in laryngeal rupture and carotid artery stenosis: the "Isadora Duncan syndrome".A case report and review of literature.Emerg Med J, 2003; 20:391-3.

[5] Gupta BD, Jani CB, Datta RG. Accidental strangulation: a case report. Med Sci Law, 2004; 44:359-62.

[6] Gururaj G, Channabasavanna SM, Das BS \&Kaliaperumal VG. Epidemiology of Head Injuries in Bangalore, National Institute of Mental Health and Neuro Sciences, Bangalore, PR1993//3/93.

[7] Http://article.wn.com/view/Helmet_holiday_to_end_for_Delhi_women_OUR SPECIAL_CORRESPOND/2012/04/26

[8] Jain V. Dupatta: 2006. A unique cause of cervical spine injury in females. Available at: http://www.ioacon2006.com/conference.pdfO. Accessed November 5, 2007.
[9] Kohli A, VermaSK, Agarwal BB. 1996 Accidental strangulation in a rickshaw. Forensic Scilnt.1996; 78:7-11.

[11] Mohan D.A Study of Helmet and Motorized Two-wheeler Use Patterns in Delhi. American Association for Automotive Medicine Quarterly Journal, 1983; 29-32.

[12] Mohan D, Safer two wheelers and Helmets, International workshop on Prevention and Control of Traffic Accidents and Injuries, New Delhi, India, 1992; 143-148.

[14] Shutter LA, Kempisty SM, RN, Johannigman JA, , Narayan RK. Unhelmeted Motorcyclists: Higher Mortality, Morbidity, and Costs. Available at: http;// www. mayfieldclinic.com Accessed 26 Feb 2012.

[15] Siddiqui AA, Shamim MS, Jooma R, Enam SA. Long scarf injuries. J Coll Physicians Surg Pak. 2006; 16:152-3.

[15] Technical Books Section. Anil Aggrawal's Internet Journal of Forensic Medicine and Toxicology 2001 (July-December); 2:8. Available at: http://www.geradts. com/anil/ij/indexpapers.htmlO. Accessed November 5, 2007.

[16] Thompson DC, RivaraF, Thompson R Helmets for preventing head and facial injuries in bicyclists Accessed at http://www.thecochranelibrary.com on 12 302013. Published by JohnWiley\& Sons, Ltd 2009, Issue 1

[17] Verma SK, Aggarwal NK, Kohli A. Accidental ligature strangulation deaths in East Delhi (India). Med Sci Law 2005; 45:47-51. 